\title{
Characterization of sediment layer composition in a shallow lake: from open water zones to reed belt areas
}

\author{
I. Kogelbauer and W. Loiskandl \\ Institute of Hydraulics and Rural Water Management, University of Natural Resources and Life Sciences, Vienna, \\ Muthgasse 18, 1190 Vienna, Austria \\ Correspondence to: I. Kogelbauer (ilse.kogelbauer@boku.ac.at)
}

Received: 2 October 2014 - Published in Hydrol. Earth Syst. Sci. Discuss.: 13 November 2014

Revised: - - Accepted: 18 February 2015 - Published: 19 March 2015

\begin{abstract}
Lake sediment characterization, a prerequisite for the vulnerability assessment of lake ecosystems, demands reliable in situ methods for the characterization of the sediment layer composition. A unified characterization of lake sediments within lake ecotopes (open water, open water patches within the reed, and the reed) is still a challenge. Each ecotope is covered by different classical scientific disciplines (hydrography and terrestrial remote sensing to soil physics) with their specific characterization methods. Recently, a complementary tool that bridges the gap between land and hydrographic surveying methods was introduced. It is a non-acoustic device that combines two soil physical sensors (a capacitive sensor and a cone penetrometer) and GNSS-positioning in a measuring system (CSPS). The CSPS enables rapid in situ delineation of water-mud-consolidated lakebed interfaces. The system was successfully applied across ecotopes at the Neusiedler See, a well-mixed shallow lake rich in fine-grained sediments. The geo-referenced vertical CSPS profiles show ecotope-specific layer composition. The effects of wind-induced turbidity, particle size, and electrical conductivity were analysed. The water-mud interface was precisely delineated at the open water due to a persistent high water content gradient, equivalent to a lutocline. The penetration resistance (PR) for open water showed either a shallow and highly compacted consolidated lakebed or a consolidated lakebed with a partially compacted layer above, while in the reed the PR smoothly increased until reaching the deepest penetration depths.
\end{abstract}

\section{Introduction}

The Neusiedler See is the largest lake in Austria $\left(315 \mathrm{~km}^{2}\right)$, and comprises two different ecotopes - the open water and the reed belt $\left(178 \mathrm{~km}^{2}\right)$ (Dokulil and Herzig, 2009). This endorheic lake is well mixed and rich in fine-grained sediments that form a distinct mud layer. Owing to its shallowness and wind exposure, the open water zone is characterized by a high concentration of fine-grained suspended sediments (Dokulil and Herzig, 2009). In contrast, the water is completely clear in the reed belt of predominantly Phragmites and the open water patches within the reed, but contains a high amount of humus colloids that leads to a yellow to brownish water colour. Inorganic turbidity in the reed is completely missing for two reasons: first the extremely calm water due to less wind exposure, and secondly the chemophysical effects between the humic colloids and the finestgrained sediments. Also, the turbidity within the reed belt is only secondarily impacted by the stormy conditions at the open water due to water drift from and into the open water (Tauber, 1959).

The reed belt is for the most part an inhomogeneous patchwork of reed, open water areas, and other plants. Thus the reed was differentiated in five main classes with subtypes by age, density, amount of open water areas and the amount of other plants (Schmidt and Csaplovics, 2010). The open water patches within the reed are classified either as considerably sparse old to very old or dying reed with an open water area $>50 \%$ within the reed (class IV and V) or as open water patches with brownish water colour (Braunwasser). In the following these open water areas are labelled as "sparse reed patches" and Braunwasser. In contrast, the inner reed belt and the reed along the lake and terrestrial bor- 
ders are assigned to class III, which is defined as sparse to old closed reed with maximal $30 \%$ open water (Schmidt and Csaplovics, 2010).

The lake is part of the national park Neusiedler See Seewinkel, and as such very sensitive to human interventions. The management of a shallow lake, which is specifically prone to dynamics of extensive sedimentation, relies on extensive research on sediment layering within ecotopes. The investigation of the layer composition and the water depth is of ecological relevance for, for example, the shoreline as vegetation-water interaction zones. Siltation at the shoreline enables the expansion of reed growth. Moreover it affects the structure and vitality of littoral vegetation such as the reed (Csaplovics et al., 1996). The sediment layer compositions are not uniformly distributed over the lake and the regional differences may result from water level changes, wind influences, and biological changes (Preisinger, 1979). Horizontal lake management suggests that a lake risk assessment should incorporate the vulnerability of the reed belt and wetlands around the lake (Soja and Soja, 2014). Lake sediment investigations represent a powerful tool for the support of lake risk assessment in view of changing climate conditions and human impacts (Tolotti, 2012). The layer composition of water-mud-consolidated lakebed sediment of ecotopes needs to be characterized. Thus the investigation of the sediment layer composition requires a reliable in situ method where the same sediment body is investigated from terrestrial and water sites.

Near-surface geophysical methods are commonly used to provide detailed stratigraphic information on the sediment body by means of high-resolution spatial images. But Missiaen et al. (2008) stated that a blank data spot remains at the land-water transition where the land-based and the marine geophysical techniques do not converge. Thus, the test of different geophysical techniques (marine sub-bottom profiling, seismic reflection measurements, geo-electrical and electromagnetic measurements, cone penetration test, and manual coring) indicated that no single technique but only an integrated use can provide relevant information. The acoustic methods, especially echo sounding, provided the most comprehensive spatial interpretation of sedimentary structure together with the valuable ground-truth information of the penetration test and the coring (Missiaen et al., 2008). Acoustic echo sounding techniques are widely used for spatial scanning of the bed-topography in marine and lake environments, usually in order to ensure the navigability of shipping pathways (McAnally et al., 2007; Schrottke et al., 2006). But in environments rich in fine-grained sediments the interpretation of the sediment structure - especially the delineation of the mud layer - is challenging and requires measurements of sediment properties at appropriate resolution (Lambert et al., 2002; Schettini et al., 2010). Hence, additional measurements are performed with optical or acoustic sensors to derive the suspended solids concentrations (SSCs) (McAnally et al., 2007; Schettini et al., 2010; Shi et al., 1996; Teeter,
1992; Wolanski et al., 1989), non-acoustical direct devices such as cone penetration testing with pore pressure measurement (Seifert and Kopf, 2012; Seifert et al., 2008), or the coring for the ground truth (Lambert et al., 2002). The additional information aims to improve the layer delineation along a continuous vertical profile of sediment properties showing distinctive interfaces of water-mud-consolidated lakebed sediment. However, those methods were only applied at the open water.

Thus, a combination of soil physical sensors in a measuring system (combination of soil physical sensors, CSPS) was introduced in Kogelbauer et al. (2013), providing continuous and georeferenced vertical profiles by in situ measurements. The system combined two commonly applied soil physical sensors, a capacitive sensor and a cone penetrometer (CP), synchronized with Global Navigation Satellite System with Real-Time Kinematic (GNSS RTK) positioning. It enabled the layer delineation of water-mud-consolidated lakebed sediment due to the striking differences in the interface characteristics. The water-mud interface is delineated by a distinct decrease in the water content determined by the capacitive sensor (Hydra Probe), equivalent to a lutocline. The lutocline is defined as a high-density gradient at the interface between clear water on top and the mud suspension underneath (Wolanski et al., 1989). Further the interface mud-consolidated lakebed sediment is delineated at significant penetration resistance (PR) measured with the CP. The method was cross-validated by comparison with echosounding data (Heine et al., 2013, 2014) and by ground-truth information from shallow cores. The CSPS was successfully applied in the shallow Neusiedler See.

The designed CSPS was applied at the lake's different ecotopes: (1) the open water area for referencing echo sounding (Heine et al., 2013, 2014), (2) the shallow water areas below $0.5 \mathrm{~m}$ to describe the shoreline topography, and where echo sounding is not working, (3) the sparse reed patches and the open water patches of brownish colour (Braunwasser) within the reed, and (4) within the reed. The evidence suggests that CSPS represents a useful complementary tool that bridges the gap between land and hydrographic surveying methods.

The objective of this paper is to characterize the layer composition of the different ecotopes obtained from the CSPS profiles. Additionally, relevant parameters (electrical conductivity and particle size) and wind as affecting external factors are discussed.

\section{Methods}

\subsection{CSPS in a measuring system and its performance in the field}

The CSPS in a measuring system was designed for sediment layer delineation in shallow lakes, described in Kogelbauer et al. (2013) (Fig. 1, left panel). It combines two commonly 

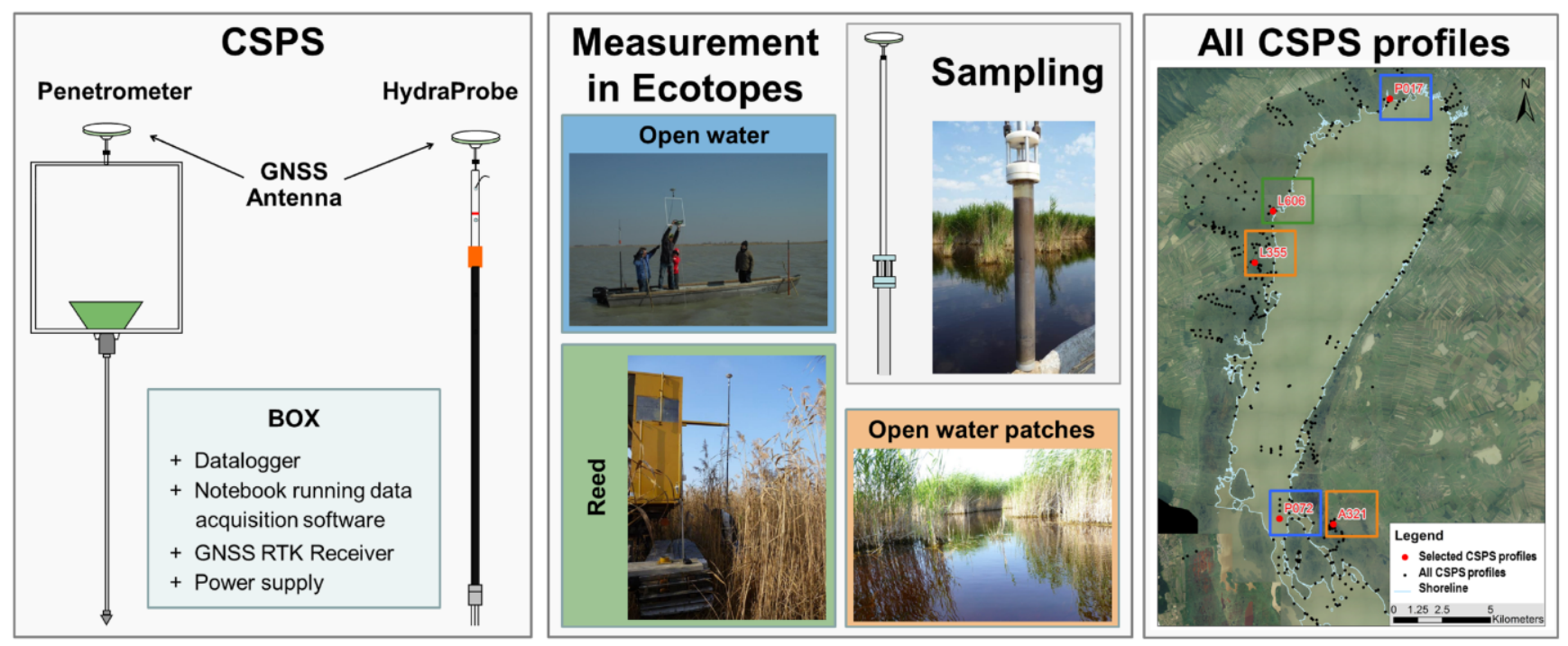

Figure 1. Overview showing the designed system (CSPS), the measurement in the different ecotopes in representative pictures, the sampling equipment, and all measured CSPS profiles at the study site, the Neusiedler See. The selected ecotope-specific CSPS profiles are shown as red circles.

applied soil physical sensors: a capacitive sensor for indirect water content measurements and a modified CP for PR measurements. The capacitive sensor, the Hydra Probe (Stevens Water Monitoring System) is based on frequency domain reflectometry (FDR) at $50 \mathrm{MHz}$ and measures the dielectric permittivity $\varepsilon_{r}$ to indirectly indicate the volumetric water content $\theta$. The modified CP (Eijkelkamp) measures the PR. The two sensors were combined with GNSS RTK positioning for dynamic vertical profile measurements with precise location information $(x, y, z)$ of $\pm 35 \mathrm{~cm}$ in overall accuracy. The GNSS antenna was mounted on top of both sensors.

The measurement procedure of the CSPS was similarly conducted at all sites: the open water area, the shallow water areas below $0.5 \mathrm{~m}$, the open water patches within the reed, and within the reed itself (Fig. 1, middle and right panels). The sensors were consecutively used at the same site to create an instantaneously vertical profile in water, mud and consolidated lakebed sediments. The Hydra Probe (HP) measurement started with the sensor head and its tines still in the air. After a few seconds the sensor was slowly inserted in the water and continuously submerged until the compacted mud prevented further penetration of the sensor.

The CP measurement started in the layer where minimal pressure resistance was detected. The sensor was slowly submerged as far as the consolidated lakebed and deeper when a maximum resistance was reached. The layers of compacted mud and the consolidated lakebed sediments were indicated by a rapidly increasing PR.

Each sensor measurement was repeated at least three times for the same area to consider local variability of the mud layer structure and the lake bottom topography. At the open water surface 712 measurements were taken at 63 prede- fined echo sounding reference points, using a small boat tied to stakes. At the shoreline, 2103 measurements were taken along 153 short transects, starting with a point in the reed, continuing at the transition from the reed to the open water surface, and finally measuring at the open water. This enabled a description of the lakebed topography at the transition from reed to the open water. The shoreline at the open water patches within the reed was similarly investigated with additional points randomly placed at the open water area of these patches (1605 measurements at 154 sites). Apart from the investigations by boat at the open water and open water patches, within the reed belt of sparse to closed old reed (class III), according to Schmidt et al. (2010), 1307 measurements at 182 sites were performed from a modified reed cutting machine along transects from the land along the reed to the lake. In total 5727 measurements at 552 sites were performed and additionally 78 cores were sampled.

\subsection{Core sampling and analysis}

Sedimentological data were derived from shallow manual coring using a hand core sampler with polycarbonate core tubes. In total 78 cores were collected together with the measured CSPS profiles. These cores were qualitatively described (colour, consistency, and roots) and thus divided into samples of the same qualities. The resulting 141 sediment samples were quantitatively analysed (particle size distribution, total and inorganic carbon, total nitrogen, $\mathrm{pH}$, electrical conductivity, particle density, mineralogy). Two water samples from the open water and 57 water samples from the reed belt were analysed for their $\mathrm{pH}$ and electrical conductivity. The aim was to calibrate the HP and to pinpoint the sedimentary succession. 
The grain size analysis was made according to the ÖNORM L 1061-1 (Austrian Standards, 2002b) and L 10612 (Austrian Standards, 2002a) to determine the predominant fine-sediment grain size classes (Sand (S) from 2 to $0.063 \mathrm{~mm}$, silt (U) from 0.063 to $0.002 \mathrm{~mm}$, and clay (C) below $0.002 \mathrm{~mm}$ ). The sand fraction was removed by wet sieving and the mass fraction of silt and clay was separated by the pipette method after Kubiena. The texture was classified according to ÖNORM L 1050. Before the chemical analysis, the sediment samples were oven dried $\left(105^{\circ} \mathrm{C}\right)$ and sieved ( $2 \mathrm{~mm}$ sieve). Some methods required a filtrate of a sediment suspension. The sediment suspension was made of sediment and distilled water, shaken well, and finally filtrated. The $\mathrm{pH}-$ value of the sediment samples was measured according to the Austrian Standard ÖNORM L 1083 (Austrian Standards, 2005), whereas in the water samples it was measured immediately without further preparation requirements. The electrical conductivity was measured in the filtrate of the sediment samples, whereas it was directly measured in the water samples.

\subsection{Data acquisition software and analysis}

Data from the sensors and the GNSS RTK were collected and processed with a data acquisition system. For this, software (GeneCon) was programmed in $\mathrm{C \#}$ as the main part of the data acquisition system (see also Kogelbauer et al., 2013). Additional software (GenePost) was programmed for post processing. GenePost comprises a conversion tool responsible for raw data conversion into standardized physical values $\left(\varepsilon_{r}, \theta\right.$, PR) by utilizing specific calibration functions (Kogelbauer et al., 2013). The GNSS position coordinates are transformed to the cartographic projection UTM (Universal Transverse Mercator) on the base of WGS 84 (World Geodetic System 1984). The second part of GenePost is a utilization tool that performs the smoothing function of the penetrometer measurements, the layer detection, the compilation for a digital elevation model (DEM), and some additional graphical features assisting the graphical data validation.

The calibration functions of the sensors - the HP (D'Amboise, 2012) and the CP (Kogelbauer et al., 2013) - were embedded in the conversion tool. The implemented PR function (MPa) was improved in the software, and considered the actual weight of the variable probing rod length $R_{\mathrm{p}, x}$, which resulted in a varying offset of the PR measurements.

For the layer detection in GenePost the raw data of the CP measurements were smoothed by delineating outliers, e.g. negative and/or extremely low PR peaks occurring during short force release during pushing of the CP. The measurements were sorted according to their height to get a monotone decreasing function of the height and to eliminate loops. Those loops with small height appeared due to the dynamic reaction (fast moves) of the GPS during the measurement. Finally, the actual smoothing was undertaken, therefore the maximum PR within each interval of $2 \mathrm{~cm}$ height was selected. The height diversion started once from the topmost and once from the bottommost point to include all points and also the last lowest maximum PR. An interval height of $2 \mathrm{~cm}$, according to the maximum GNSS accuracy, was considered the best. The HP measurements provide very smooth data sets, hence no smoothing was necessary.

\section{Results and discussion}

The characteristic layer compositions are presented for the different ecotopes at the shallow, endorheic Neusiedler See: (1) the open water area (see Heine et al., 2014), (2) the open water patches within the reed - sparse reed patches and Braunwasser, and (3) the reed.

The influence of external factors such as chemical parameters, wind, electrical conductivity, and particle size is discussed sequentially as occurring from top to bottom in the accompanying layer.

The characteristics and important features are highlighted in a representative CSPS profile, illustrated in Fig. 2. It contains the volumetric water content $\theta\left(\mathrm{m}^{3} \mathrm{~m}^{-3}\right)$ (top blue scale), which is indirectly indicated by the HP due to sitespecific calibration considering different mud layer composition across the lake. This parameter marks the difference between water and mud very precisely. Moreover, it reveals information on other aspects such as inorganic turbidity, electrical conductivity, and sand fraction. The water content reading for the lake water is always lower than 1 because of the inorganic turbidity, especially in the open water, and the variable ecotope-specific electrical conductivity. The HP calibration was done for the mud layer to compensate for varying mud layer composition throughout the lake, and not for the lake water itself.

The HP sensor measurement starts in air and indicates the air-water interface by an increase in $\theta$ from zero (air) to about 0.94 (lake water), which is only used as ancillary information. After the sensor submersion in water at an almost constant volumetric water content value $\theta_{\text {Water }}$, a striking decrease in $\theta$ to considerably smaller values indicates the water-mud interface, equivalent to a lutocline (see Fig. 2). The lutocline is defined as a high density gradient at the interface between clear water on top and the mud suspension underneath (Wolanski et al., 1989). It can occur in turbid environments rich in fine-grained sediments, marine as well as freshwater. It is manifested in a sharp step structure in the vertical profiles of the suspended sediment concentrations or density, which is present even in the absence of the vertical gradients of temperature and salinity (McAnally et al., 2007; Metha and McAnally, 2008; Schettini et al., 2010; Wolanski et al., 1989).

After the water-mud interface detection, the ongoing HP submersion in the mud suspension might highlight the stratification within the layer and finally stops when the me- 


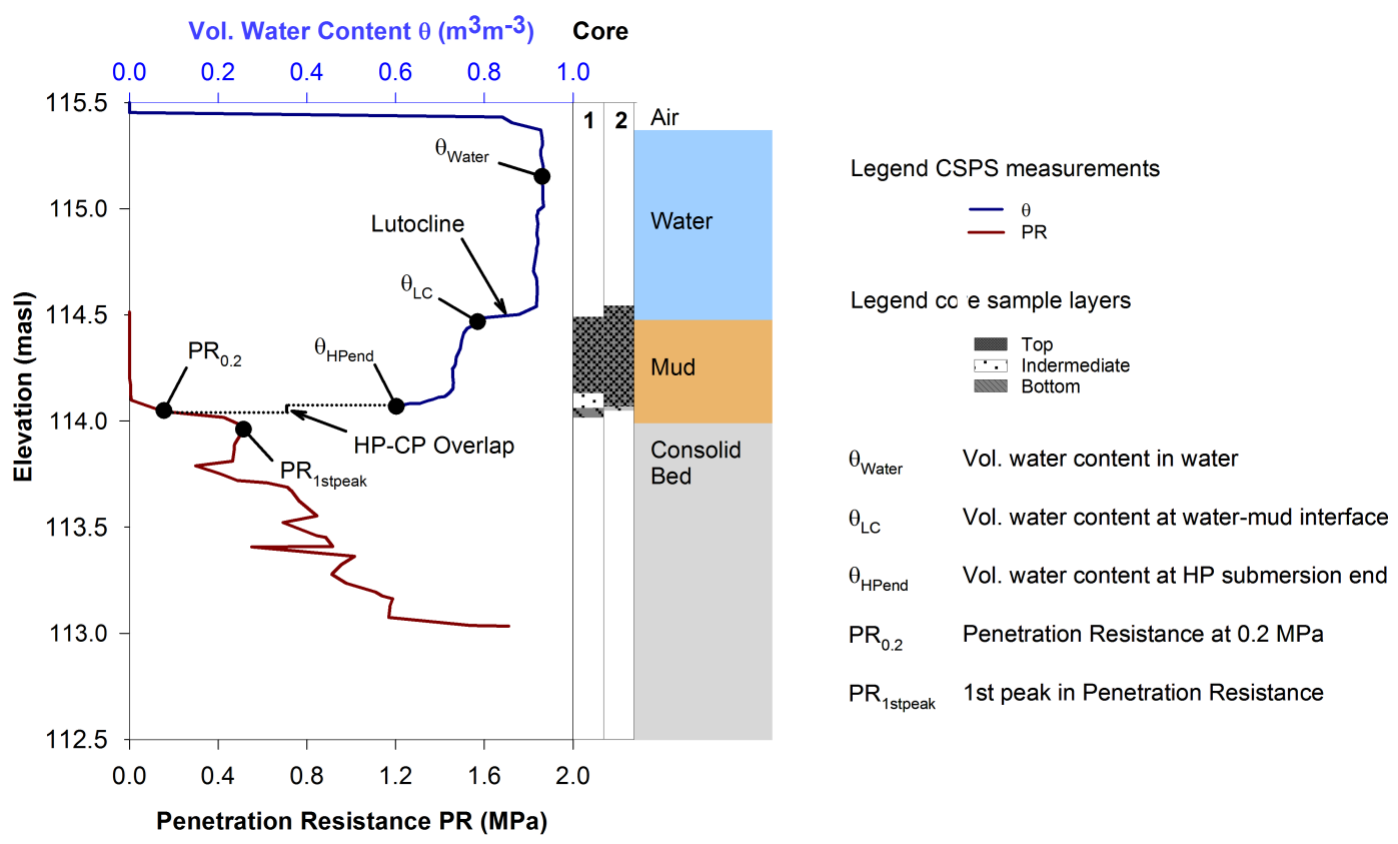

Figure 2. Characteristic features highlighted in a typical CSPS profile.

chanical resistance prevents further penetration of the sensor. Later, the water content at the HP submersion end $\theta_{\mathrm{HP}}$ end is correlated to the sand fraction of the core samples. Almost concurrently the penetrometer starts registering the incipient $\mathrm{PR}, \mathrm{PR}_{x}$, and increases until the first significant peak

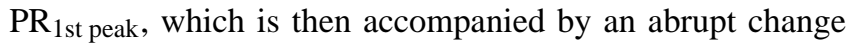
in slope. The $\mathrm{PR}_{0.2}$ at $0.2 \mathrm{MPa}$ is an empirically set value where the layer detection algorithm starts. The HP and CP measurements overlap in height at $\theta_{\mathrm{HP}}$ end and $\mathrm{PR}_{0.2}$ (see Sect. 3.4). The first peak $P_{1 \text { st peak }}$ is stated to indicate already fully consolidated lakebed sediment, i.e. the lake bottom. Apparently, this is the interface of a suspension at top, where no effective stress is measured, and the underlying consolidated bed sediment with already measurable effective stress (Metha and McAnally, 2008). Occasionally, a rather distinctive intermediate partially consolidated layer may occur between $\mathrm{PR}_{0.2}$ and the first peak $\mathrm{PR}_{1 \text { st peak }}$, depending on the location. The penetrometer detects a consolidated lakebed sediment layer by a constant slope of the PR due to the equal friction within that layer of the same properties. In contrast, a peak accompanied by a change in the gradient indicates a change of the sediment properties and hence indicates another sediment layer. The sediment sample layers from coring and the layer delineation are shown next to the CSPS profile. The sediment samples were qualitatively separated (particle size, consistency, and colour) in bottom, intermediate, and top layers.

\subsection{Wind effect on $\theta_{\text {Water }}$ at the open water due to upward diffusion}

Fine sediments are stirred up at wind velocities of less than $10 \mathrm{~km} \mathrm{~h}^{-1}$ and cause permanent inorganic turbidity in the wind-exposed open water (Dokulil, 1983). However, a gentle turbidity always remains at the open water even at calm wind conditions due to the immanent suspended finest-grained sediments (Sauerzopf and Tauber, 1959); thus, the measured $\theta$ Water is always below 1 .

During the measurement campaign at the open water surface, which was conducted within 9 days in spring 2012 and 1 day remeasurement in summer 2013, it was recognized that the $\theta_{\text {Water }}$ value was influenced by the wind conditions of a preceding period of a few days. In Fig. 3, HP measurements at point P072, which were conducted on a calm day and a windy day with high turbidity, are compared to show the wind effect. $\theta_{\text {Water was about }} 0.94 \pm 0.02$ in calm wind conditions; it was high when the mud accumulation was low and vice versa. During windy conditions $\theta_{\text {Water }}$ was significantly reduced $(<0.9 ; 0.7-0.8)$ by the increasing amount of suspended sediments in water due to upward diffusion from the mud layer. Small regional differences were recognized, depending on the amount of finest-grained sediments.

Nonetheless, the absolute height of the water-mud interface still remained, but the lutocline, i.e. the water content gradient, was less pronounced (Fig. 3). Still, the lutocline was always significant and guaranteed precise layer detection. The finding that the lutocline persists even under significant flow-induced forcing, such as strong wind, coincides with Metha and McAnally (2008). Moreover, the time in- 
Table 1. $\theta_{\mathrm{HP}}$ end related to the amount of sand fraction at the open water.

\begin{tabular}{lrrrrr}
\hline & $\begin{array}{r}p[\mathrm{~S}] \\
(\%)\end{array}$ & $\begin{array}{r}p[\mathrm{U}] \\
(\%)\end{array}$ & $\begin{array}{r}p[\mathrm{C}] \\
(\%)\end{array}$ & $\begin{array}{r}\theta_{\text {Water }} \\
\left(\mathrm{m}^{3} \mathrm{~m}^{-3}\right)\end{array}$ & $\begin{array}{r}\theta_{\text {HP end }} \\
\left(\mathrm{m}^{3} \mathrm{~m}^{-3}\right)\end{array}$ \\
\hline Sand fraction $S>6 \%$ & 39.73 & 22.80 & 37.48 & 0.95 & 0.54 \\
& $(27.65)$ & $(9.32)$ & $(18.88)$ & $(0.01)$ & $(0.03)$ \\
\hline Sand fraction $S<6 \%$ & 2.38 & 39.08 & $\begin{array}{r}58.54 \\
(7.79)\end{array}$ & $\begin{array}{r}0.90 \\
(0.07)\end{array}$ & $\begin{array}{r}0.58 \\
(0.05)\end{array}$ \\
\hline
\end{tabular}

Without measurements of two extraordinary sites of high electrical conductivity or sand fraction $>90 \%$ (located at Rust and Vogelinsel, respectively); average value and below standard deviation in parentheses; sediment grain size classes: sand (S) from 2 to $0.063 \mathrm{~mm}$, silt (U) from 0.063 to $0.002 \mathrm{~mm}$, and clay (C) below $0.002 \mathrm{~mm}$

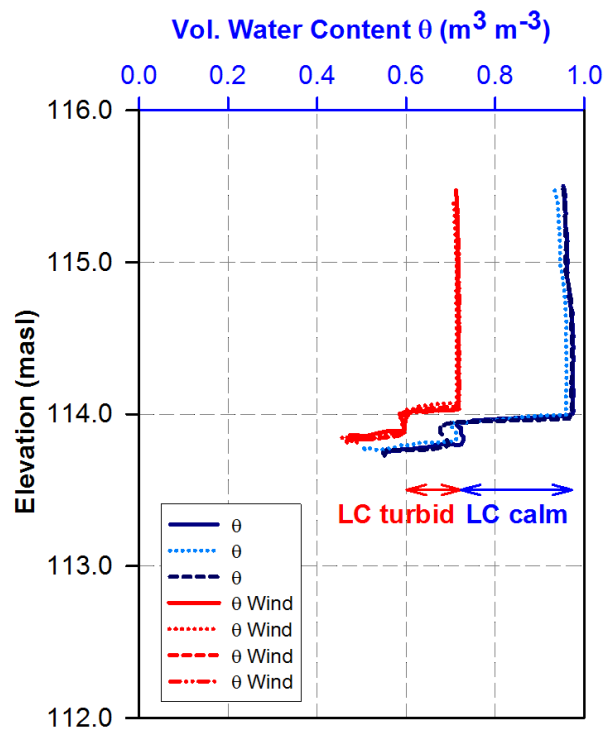

Figure 3. Volumetric water content $\theta_{\text {Water }}$ and the lutocline LC are affected by the wind-induced upward diffusion: the lutocline LC, which indicates the water-mud interface, is more pronounced during calm conditions ( $\theta$, LC calm, blue) than during windy conditions ( $\theta$-Wind, LC turbid, red). The absolute height of the interface is not wind-affected. A good repetition of several consecutive measurements is shown too.

dependence of measurements within two consecutive years was addressed, since $\theta$ was measured in 2012 and $\theta$-Wind was measured in 2013. The measured absolute layer heights from consecutive years remained within the overall system accuracy.

\section{2 $\theta_{\mathrm{HP}}$ end $\mathrm{vs.} \mathrm{sand} \mathrm{fraction} \mathrm{at} \mathrm{the} \mathrm{open} \mathrm{water}$}

Another important aspect is that the volumetric water content at the HP submersion end $\theta_{\mathrm{HP}}$ end, where the mechanical resistance prevents further progress, is subject to the amount of sand fraction at the corresponding height. The average $\theta_{\mathrm{HP}}$ end was generally lower in the presence of at least $6 \%$ sand fraction in the clay- and silt-dominated environment (Table 1).
Remarkably, some measurements of low $\theta_{\mathrm{HP}}$ end values at almost no sand fraction in the corresponding core sample showed extremely high electrical conductivity in the lakebed-sediment filtrate (located at Rust).

\subsection{Selected chemical parameters and soil texture of the ecotopes}

The Neusiedler See can be classified as a sodium bicarbonate lake, containing now up to $2 \mathrm{~g} \mathrm{~L}^{-1}$ of salts (Herzig and Dokulil, 2001). Generally, electrical conductivity is 1300 $3200 \mu \mathrm{S} \mathrm{cm}^{-1}$ and $\mathrm{pH}>8$ (Herzig and Dokulil, 2001), but these vary across the ecotopes with completely different environmental conditions.

The chemical analysis of the water samples in the reed area at the western shore showed an average electrical conductivity of $2061 \mu \mathrm{S} \mathrm{cm}^{-1}$, which was significantly higher than the average of $727 \mu \mathrm{S} \mathrm{cm}^{-1}$ in the open water area (Table 2). The $\mathrm{pH}$ of water within the reed was 7.5 and therefore also lower than that of the open water ( $\mathrm{pH} 8.7$ ).

The chemical analysis of the sediment sample filtrates showed the highest electrical conductivity for those from the reed and the highest $\mathrm{pH}$ for samples from the Braunwasser, which were located to the south-east in the national park area (Table 2). The total carbon $\mathrm{C}_{\text {tot }}$, total nitrogen $\mathrm{N}_{\text {tot }}$, and electrical conductivity were higher in the reed than at the open water area (unpublished results), whereas $\mathrm{pH}$ was almost similar. The results from the particle size analysis are shown within the Austrian soil texture triangle (Fig. 4). In Fig. 4 all samples (without height separation - bottom, intermediate, and top layers) are shown and highlighted a highly clay (C)dominated environment at the open water, a loamy clay (IC) to silty loam (sL) environment at the sparse reed patches in the north-west surrounding the Wulka River mouth, and an IC to clayey sand (cS) environment in the Braunwasser in the south-east.

\subsection{HP-CP overlap of the vertical measurement range from the Hydra Probe and the $\mathrm{CP}$}

The HP-CP overlap depicts the height difference ranging from the HP submersion end to the first significant PR signal 


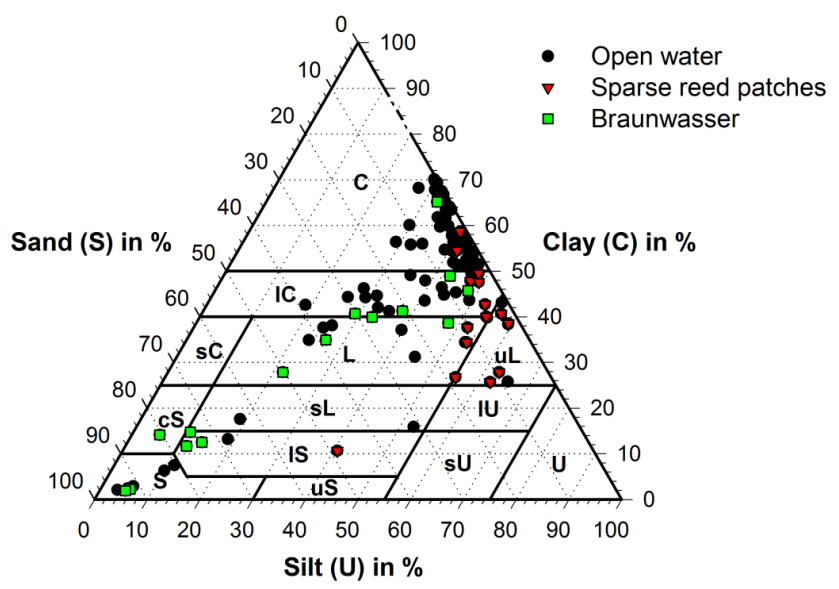

Figure 4. Soil texture triangle (after ÖNORM L 1050) including all ecotope-specific sediment samples. It highlights a highly claydominated environment, especially at the open water. A trend to clay content below $50 \%$ is evident for the water patches within the reed.

$\mathrm{PR}_{0.2}$ at $0.2 \mathrm{MPa}$ for the nearest neighbouring measurement of each sensor (Fig. 2). The maximum distance to the nearest measurement neighbour is set to $0.5 \mathrm{~m}$. This HP-CP overlap for the open water area was in average $-0.02 \mathrm{~m}$ (standard deviation, SD, 0.19), so the penetrometer's first detection signal lies above the last HP signal. Hence, a continuous vertical profile was supported by the combination of those two sensors. In the reed the average overlap of about $-0.09 \mathrm{~m}$ (SD 0.30) was even bigger than at the open water area. This is explained by an early but small penetration signal, while pushing through the top rhizome layer (see also Fig. 6e). These early signals fade quickly and soon increase to significant values of PR at the lake bottom.

\subsection{Consolidated lakebed - knick point in PR}

According to Metha and McAnally (2008), the bed can be differentiated from the mud suspension above by the measurable effective normal stress. The measurable stress is partially nil above the lakebed surface and increases below it with increasing concentration or density. Above the fully consolidated bed showing already considerable effective stress, a newly deposited or partially consolidated layer shows gradually increasing effective stress and may still undergo deformations (Metha and McAnally, 2008; Whitehouse et al., 2000).

Thus, the consolidated lakebed is defined as the first significant peak or knick point in the $\mathrm{PR}_{1 \text { st peak }}$ higher than $0.8 \mathrm{MPa}$, frequently together with an abrupt change of slope, i.e. less increase in PR with increasing penetration depth. The knick point in PR is typically due to a change in friction that indicates changing sediment properties.

The above partially consolidated layer ranges from the signal $\mathrm{PR}_{0.2}$ at $0.2 \mathrm{MPa}$ (discussed in Sect. 3.4) to the defined
Table 2. Chemical parameters ( $\mathrm{pH}$, electrical conductivity) for all sediment and water samples.

\begin{tabular}{|c|c|c|c|}
\hline Average & $\mathrm{pH}$ & $\begin{array}{r}\text { Electrical } \\
\text { conductivity } \\
\left(\mu \mathrm{S} \mathrm{cm}^{-1}\right)\end{array}$ & $N$ \\
\hline \multicolumn{4}{|c|}{ Sediment samples } \\
\hline Open water & $\begin{array}{r}8.6 \\
(0.2)\end{array}$ & $\begin{array}{r}725 \\
(230)\end{array}$ & 81 \\
\hline Sparse reed patches & $\begin{array}{r}8.1 \\
(0.3)\end{array}$ & $\begin{array}{r}812 \\
(602)\end{array}$ & 18 \\
\hline Braunwasser & $\begin{array}{r}9.1 \\
(0.3)\end{array}$ & $\begin{array}{r}591 \\
(304)\end{array}$ & 16 \\
\hline Reed & $\begin{array}{r}8.4 \\
(0.3)\end{array}$ & $\begin{array}{r}1003 \\
(303)\end{array}$ & 18 \\
\hline \multicolumn{4}{|c|}{ Water samples } \\
\hline Open water & $\begin{array}{r}8.7 \\
(0.0)\end{array}$ & $\begin{array}{r}727 \\
(8)\end{array}$ & 2 \\
\hline Reed & $\begin{array}{r}7.5 \\
(0.3)\end{array}$ & $\begin{array}{r}2061 \\
(901)\end{array}$ & 57 \\
\hline
\end{tabular}

Average value of ecotope-specific samples (without height separation); SD in parentheses; $N=$ sample size.

$\mathrm{PR}_{1 \text { st peak }}$ signal at $0.8 \mathrm{MPa}$. The height of the partially consolidated layer at the open water area was on average $0.24 \mathrm{~m}$ (SD 0.23) and may reach up to $1.34 \mathrm{~m}$ in maximum. It is considered to be the incipient state of consolidation formed either due to settling or due to an evolving pore structure where the cone penetration force is already diverted (Whitehouse et al., 2000). Thus, this intermediate layer is on the point of losing the characteristics of a water-driven mud suspension at the open water.

The shape of the penetration function is affected by numerous factors, such as the particle size distribution, the windinduced current, the organic content, the sediment mineralogy, and the consolidation and coagulation processes. However, about four main penetration signal types, A to D, are predominantly found. Signal types A and B mainly occur at the open water area, signal type $\mathrm{C}$ occurs at the open water patches within the reed, and signal type $\mathrm{D}$ predominantly occurs in the reed (Fig. 5).

At the open water area, the penetration type correlates to the particle size distribution. Type A shows a consolidated lakebed at the knick point of $\mathrm{PR}_{1 \text { st peak }}$ at about $0.8 \mathrm{MPa}$ and above a partially consolidated layer of intermediate resistance. This type mainly occurs at a distinct mud layer and no, or a small amount of, sand fraction. In other words, if the clay fraction is $>50 \%$ mass, the knick point $\mathrm{PR}_{1 \text { st peak }}$ occurs at about $0.8 \mathrm{MPa}$ at a steep slope, i.e. less increasing PR at a high increase in penetration depth $(\Delta \mathrm{PR} \ll \Delta h)$. If the silt content equals the clay content or the sand fraction is higher than $3 \%$, the $\mathrm{PR}_{1 \text { st peak }}$ is at about $1 \mathrm{MPa}$, which displays Type B (Fig. 5). In this case, the slope is flat and PR rapidly 


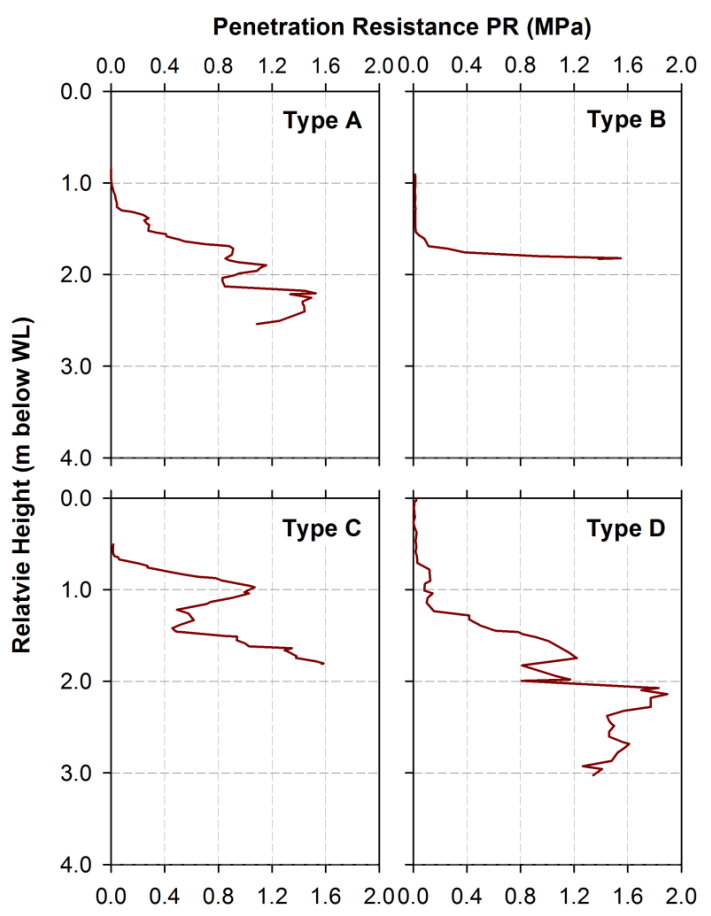

Figure 5. Compilation of the main penetration signal types. They are shown relative to the prevailing water level (WL) at the actual measurement.

increases at small penetration depth $(\Delta \mathrm{PR} \gg \Delta h)$. The discrepancy of the height difference from the existing peak at about 1.0 MPa to the defined lake bottom at $0.8 \mathrm{MPa}$ is negligible. The reason is the flat slope and the therefore marginal height difference. This thin, highly compacted lakebed layer prevents further penetration due to a high degree of compaction, which agrees with the echo sounding results showing strong and clear reflection (Heine et al., 2014).

Type $\mathrm{C}$ occurs at the less wind exposed open water patches - sparse reed patches and Braunwasser - within the reed. The consolidated lakebed is clearly defined by the $\mathrm{PR}_{1 \text { st peak }}$ with an abrupt change in slope. Small subsurface strata of weak PR occur. Type D is predominant in the reed with the characteristic small incipient PR caused by penetrating the top rhizome layer. The PR increases progressively with deep penetration. This is followed by a rapid increase from 0.8 to $1.5 \mathrm{MPa}$ or even higher accompanied by a slope change

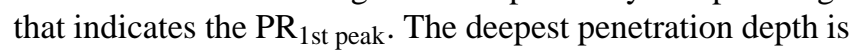
reached in the reed.

\subsection{Ecotope-specific characteristics of the CSPS profiles}

Finally, the ecotope-specific CSPS profiles (overview in Fig. 1, right panel) are shown and discussed concerning their characteristics (Fig. 6). According to the reed classification used in Schmidt et al. (2010), the selected ecotope points within the reed are assigned as followed: L355 is assigned to considerable sparse old reed (class IV) already close to the Braunwasser, A311 is in a large area of Braunwasser, and L606 is assigned to sparse old reed (class III).

At the open water area, the inorganic turbidity of the suspended sediment load in water is immanent and increases with wind. This corresponds to the measured $\theta_{\text {Water }}$ at the open water, which remained always below 1 (Fig. 6a and b). At the open water a distinct lutocline allows a precise delineation of the water-mud interface because of a gradient in water content $>10 \%$ from $\theta_{\text {Water }}$ to $\theta_{\mathrm{LC}}$ (Table 3; Fig. 6a and $b$ ). The water content at the submersion end $\theta_{\mathrm{HP}}$ end is affected by the particle size distribution (see Sect. 3.2). The extent between $\mathrm{PR}_{0.2}$ and $\mathrm{PR}_{1 \text { st peak }}$ suggests the presence of a partially consolidated layer that may undergo deformations and depends on the wind exposition and the potential of sediment accumulation. Likewise, the PR function as well as the resistance peak $\mathrm{PR}_{1 \text { st peak }}$ at the open water depends on the predominant current, the predominant particle size distribution, and the organic content as well as the mineralogical composition. The comparison of two open water sites displays some perceptible trends of the PR. Strata detection is pronounced according to the current exposition of the measuring site. Large mud layer accumulation correlates with strata detection; for example, highly consolidated mud and deeper possible penetration (Fig. 6a). On the other side, a small mud layer corresponds to rapid increase in PR due to high sand and silt content and a pronounced peak (Fig. 6b). This is also supported by the particle size distribution of the sediment cores (Fig. 7). The CSPS profiles at the open water were used for layer validation of echo sounding data (Heine et al., 2013, 2014). The layer validation considerably coincided in both the detected water-mud interface and the consolidated lakebed.

At the sparse reed patches $\theta_{\text {Water }}$ was higher than at the open water due to the missing inorganic turbidity in the extremely calm water (Table 3), which also prevails during stormy conditions (Dokulil and Herzig, 2009; Sauerzopf and Tauber, 1959) (Fig. 6c). On the contrary, in the Braunwasser (also calm) $\theta_{\text {Water }}$ was about 0.86 due to the high electrical conductivity (Fig. 6d). The penetration depth was lower in the middle of the open water patches than at its shore to the reed. The layer between $\mathrm{PR}_{0.2}$ and $\mathrm{PR}_{1 \text { st peak }}$ was on average $0.26 \mathrm{~m}$ (SD 0.24) and suggested a partial consolidation. The core samples taken at the Braunwasser (located southeast in the national park area) showed higher content of sand fraction than those from the sparse reed patches (north-west surrounding the Wulka River mouth) (Fig. 7).

In the reed areas, the volumetric water content $\theta_{\text {Water }}$ was on average 0.80 due to damping of the dielectric permittivity $\varepsilon_{r}$ by a relatively high electrical conductivity (Table 3 ). The root system in the reed limits the development of a lutocline, and thus disrupts precise mud layer delineation. However, a decreasing trend until $\theta_{\mathrm{HP}}$ end of about 0.70 on average was still given, whereas $\theta_{\mathrm{HP}}$ end at the open water areas declined to an average of about 0.57 . Reasons for this are the mea- 
A) Open water: P017, Jois

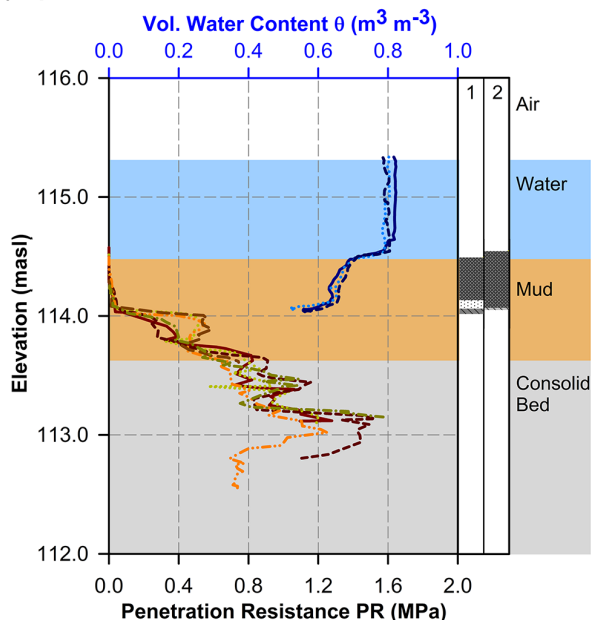

C) Sparse reed patches: L355, Oggau

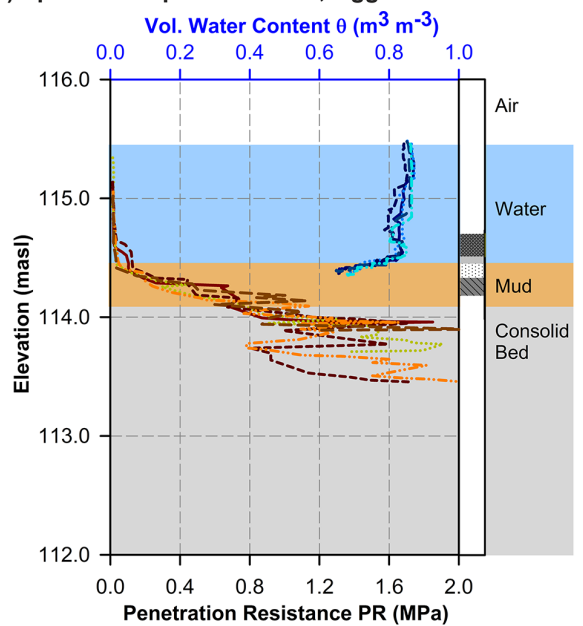

E) Reed: L606, Oggau

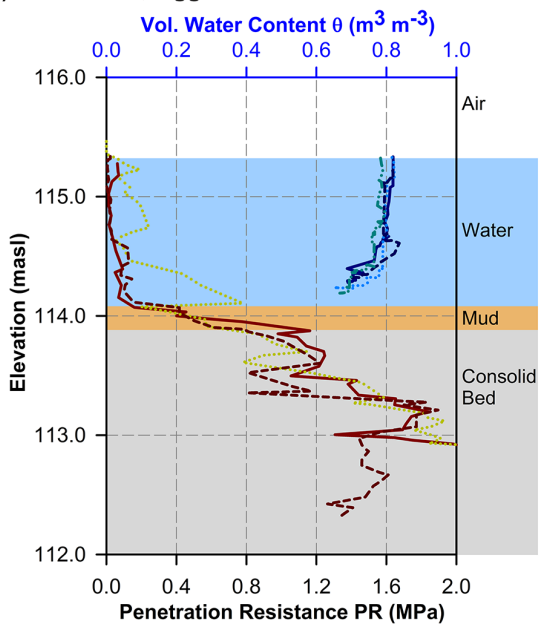

B) Open water: P072, Sandeck

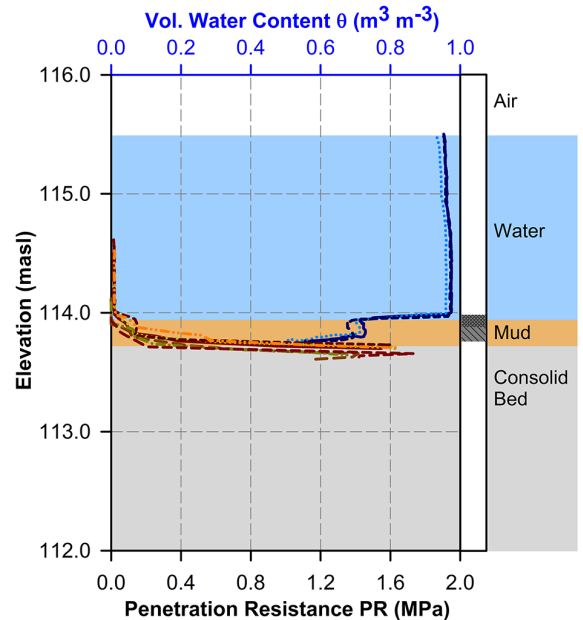

D) Braunwasser: A321, IIImitz

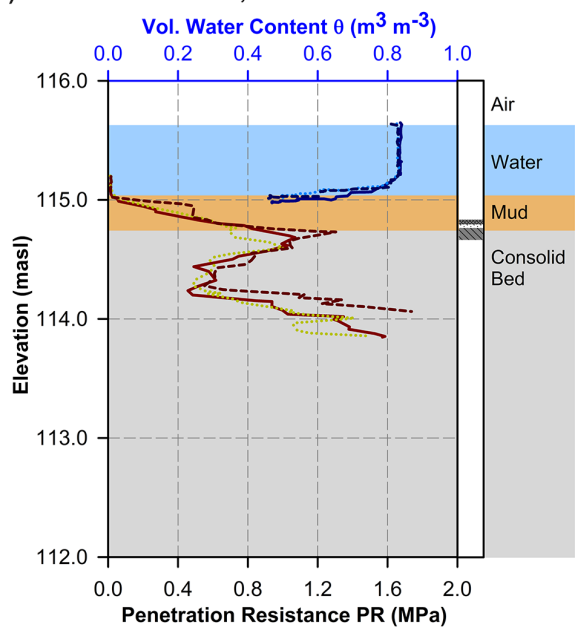

Figure 6. Representative ecotope-specific CSPS profiles for the in situ layer delineation are shown for the open water (a, b), sparse reed patches (c), Braunwasser (d), and reed (e). The HP measurement of the volumetric water content $\theta\left(\mathrm{m}^{3} \mathrm{~m}^{-3}\right)$ delineates the water-mud interface by its sudden decline. The mud-bed sediment interface is detected by the $\mathrm{PR}_{1 \text { st peak }}(\mathrm{MPa})$ at the shallowest significant peak accompanied by an abrupt change of slope. In the reed a lutocline is absent, but the mud layer composed of less consolidated sediments and rhizomes is delineated from $\mathrm{PR}_{0.2}$ to $\mathrm{PR}_{1 \text { st peak. }}$. 
Table 3. Ecotope-specific volumetric water content for water $\theta_{\mathrm{Water}}$, at the lutocline $\theta_{\mathrm{LC}}$, and at the HP submersion end $\theta_{\mathrm{HP}}$ end

\begin{tabular}{llll}
\hline Open water & Sparse reed patches & Braunwasser & Reed \\
\hline$\theta_{\text {Water }}\left(\mathrm{m}^{3} \mathrm{~m}^{-3}\right)$ & $\theta_{\text {Water }}\left(\mathrm{m}^{3} \mathrm{~m}^{-3}\right)$ & $\theta_{\text {Water }}\left(\mathrm{m}^{3} \mathrm{~m}^{-3}\right)$ & $\theta_{\text {Water }}\left(\mathrm{m}^{3} \mathrm{~m}^{-3}\right)$ \\
$\mathbf{0 . 8 7}$ & $\mathbf{0 . 9 1}$ & $\mathbf{0 . 8 1}$ & $\mathbf{0 . 8 0}$ \\
$(0.11)$ & $(0.07)$ & $(0.10)$ & $(0.12)$ \\
\hline$\theta_{\mathrm{LC}}\left(\mathrm{m}^{3} \mathrm{~m}^{-3}\right)$ & $\theta_{\mathrm{LC}}\left(\mathrm{m}^{3} \mathrm{~m}^{-3}\right)$ & $\theta_{\mathrm{LC}}\left(\mathrm{m}^{3} \mathrm{~m}^{-3}\right)$ & $\theta_{\mathrm{LC}}\left(\mathrm{m}^{3} \mathrm{~m}^{-3}\right)$ \\
$\mathbf{0 . 7 6}$ & $\mathbf{0 . 8 0}$ & $\mathbf{0 . 7 1}$ & $-^{*}$ \\
$(0.09)$ & $(0.06)$ & $(0.09)$ & $-^{*}$ \\
\hline$\theta_{\text {HP end }}\left(\mathrm{m}^{3} \mathrm{~m}^{-3}\right)$ & $\theta_{\text {HP end }}\left(\mathrm{m}^{3} \mathrm{~m}^{-3}\right)$ & $\theta_{\text {HP end }}\left(\mathrm{m}^{3} \mathrm{~m}^{-3}\right)$ & $\theta_{\text {HP end }}\left(\mathrm{m}^{3} \mathrm{~m}^{-3}\right)$ \\
$\mathbf{0 . 5 7}$ & $\mathbf{0 . 6 7}$ & $\mathbf{0 . 5 7}$ & $\mathbf{0 . 7 0}$ \\
$(0.09)$ & $(0.09)$ & $(0.11)$ & $(0.09)$ \\
\hline
\end{tabular}

Average value; standard deviation in parentheses. Sample size $N$ : open water patches (704); sparse reed patches (486); Braunwasser (182); reed (558). * Lutocline is not present.

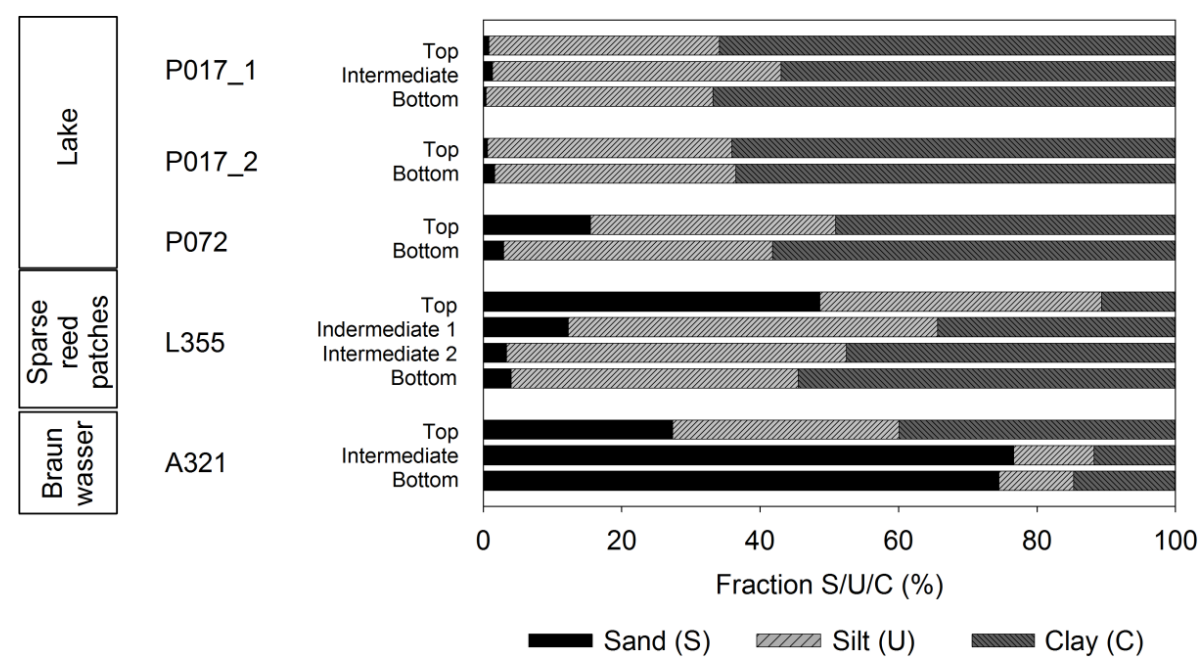

Figure 7. Particle size distribution of the ecotope-specific CSPS profiles in Fig. 6, if coring is available. The two samples at point P017 show a comparable distribution.

surements within the reed rhizome with intrinsic high organic content, as well as a shallow submersion end not below the dense rhizome stock. The declining $\theta$ indicates an increasing amount of solids and delineates together with the early but low PR a layer composed of non-consolidated suspended sediments and rhizomes. Hence a mud-rhizome layer is de-

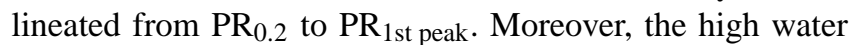
content at the submersion end $\theta_{\mathrm{HP}}$ end also justified the slow

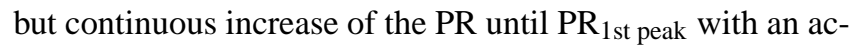
companying slope change (Fig. 6e). $\mathrm{PR}_{1 \text { st peak within the reed }}$ was mostly about 1.5 to $2 \mathrm{MPa}$. In the reed, the low degree of consolidation and the material composition support the maximal possible penetration depth compared to the other ecotopes. The particle size distribution showed generally higher content in sand fraction than at the open water. Layers rich in sand fraction of 10 up to $60 \%$ were occasionally detected in the core samples as well during the penetration.

\section{Conclusions}

Although many studies report on the exploration of sedimentary structures in marine or lake environments, a unified investigation and characterization of the sediment layer composition of the same sediment body from the transition of land to water present a challenge. The previously introduced combination of soil physical sensors in a measuring system (CSPS) provided a rapid in situ technique for the delineation of the water-mud-consolidated lakebed interfaces at different ecotopes at a shallow lake rich in fine-grained sediments. The CSPS was successfully applied in the shallow Neusiedler See and provided characteristic layer compositions for the different ecotopes (the open water, the open water patches within the reed, and the reed).

The Hydra Probe, a well-known sensor, represents a new and highly valuable device for the layer delineation of the 
water-mud interface at the open water due to a pronounced lutocline. The lutocline may be damped by factors such as a high electrical conductivity or wind-induced turbidity, but still supports precise water-mud interface delineation at the open water and the open water patches. In the reed the root system limits the development of a lutocline and thus disrupts precise mud layer delineation with the Hydra Probe.

The CP is already well known for detecting shallow subbottom strata at the open water. It was also successfully applied in the different lake environments. The delineation of the consolidated lakebed within the ecotopes is performed with the same principles but shows ecotope-specific characteristics. At the open water either a shallow and highly compacted consolidated lakebed or a consolidated lakebed with a partially compacted layer above (detected in bays located at Rust in the south-west and at some places in the north) was observed. The occurrence depends on the mud accumulation potential (predominant current, finest-grained sediment supply, wind exposure, etc.). In the reed, the PR smoothly increases, reaching the deepest penetration depths compared to the other ecotopes. The distinct layer between $\mathrm{PR}_{0.2}$ and $\mathrm{PR}_{1 \text { st peak }}$ in the reed suggests a composition of less consolidated mud and rhizome. In comparison, at the open water areas and open water patches this layer suggests partially consolidated sediments.

Overall, the study indicates that the CSPS is a powerful tool for screening shallow lake environments, and a useful complementary tool that bridges the gap between land- and hydrographic-surveying methods.

This study represents an indispensable requirement for ecosystem characterization and contributes to establishing a digital elevation model (DEM) of the mud layer and the lakebed, as part of the project "Geodetic Survey of the System Neusieder See-Hanság Channel". Nonetheless it has a stand-alone value that underlines the characteristic composition of various lake ecotopes.

This integrative approach of lake ecotope characterization supports management and ecosystem services to find a tradeoff with competing human uses. The CSPS approach is applicable in a wide range of wetlands and lake environments to characterize sediment layer compositions.

Author contributions. I. Kogelbauer designed the study, designed the method, performed research, analysed data, and wrote the paper with substantial input and edits from W. Loiskandl. W. Loiskandl conceived the study, contributed new methods, and supervised the research.
Acknowledgements. We thank Wolfgang Sokol for the technical support and software design and Erwin Heine for the support in the GNSS application. Thanks also to the measurement crew and the Biologische Station Illmitz for their technical support and facility provision. Funding for field work was granted by the European Regional Development Fund (ERDF) Cross-border Cooperation Program Austria-Hungary 2007-2013 (acronym: "GeNeSee"; project no.: ATMOS/L00130).

Edited by: A. D. Reeves

\section{References}

Austrian Standards: Physical analysis of soils - Determination of particle size distribution in mineral soils - Part 2: Fine soil (ÖNORM L 1061-2), Vienna, 2002a.

Austrian Standards: Soils from waste - Part 1: Fractional analysis Methods of analysis (ÖNORM L 1061 1), Vienna, 2002b.

Austrian Standards: Chemical analyses of soils - Determination of acidity (pH value) (ÖNORM L 1083), Vienna, 2005.

Csaplovics, E., Bácsatyai, L., Márkus, I. and Sindhuber, A.: High resolution digital terrain models of the bottom of Lake Fertö (Austria, Hungary) - a Hungarian-Austrian joint project for creating cross-border data bases for ecosystems research, International Archive of Photogrammetry and Remote Sensing, XXXI, 200-204, available from: http://www.isprs.org/ proceedings/XXXI/congress/part7/167_XXXI-part7.pdf (last access: 9 March 2015), 1996.

D'Amboise, C. J. L.: Development of Profile Measurements using a Frequency Domain Reflectometry Sensor in a Soft Sludge and Calibration for use in the Neusiedlersee, MSc Thesis, University of Natural Resources and Life Sciences, Vienna, 2012.

Dokulil, M. T.: Assessment of components controlling phytoplankton photosynthesis and bacterioplankton production in a shallow, alkaline, turbid lake (Neusiedlersee, Austria), Univeristät Wien, Wien, 1983.

Dokulil, M. T. and Herzig, A.: An analysis of long-term winter data on phytoplankton and zooplankton in Neusiedler See, a shallow temperate lake, Austria, Aquat. Ecol., 43, 715-725, doi:10.1007/s10452-009-9282-3, 2009.

Heine, E., Prokoph, A., Kogelbauer, I., and Loiskandl, W.: Hydroakustische Erfassung der Morphologie und Sedimentschichtung des Neusiedler Sees, in: 17. Internationale Geodätische Woche Obergurgl 2013, edited by: Hanke, K. and Weinold, T., Herbert Wichmann Verlag, Obergurgl, AT, 64-75, 2013.

Heine, E., Kogelbauer, I., Prokoph, A. and Loiskandl, W.: Hydrographical surveying of the steppe lake Neusiedler See - Mapping the lake bed topography and the mud layer, J. Photogramm. Remote Sens. Geoinf. Sci., 5, 339-350, 2014.

Herzig, A. and Dokulil, M.: Neusiedler See - ein Steppensee in Europa, in: Ökologie und Schutz von Seen, edited by: Dokulil, M., Hamm, A., and Kohl, J.-G., Facultas UTB, Vienna, 401-415, 2001.

Kogelbauer, I., Heine, E., D’Amboise, C., Müllebner, C., Sokol, W., and Loiskandl, W.: Adaptation of soil physical measurement techniques for the delineation of mud and lakebed sediments at Neusiedler See, Sensors (Basel)., 13, 17067-17083, doi:10.3390/s131217067, 2013. 
Lambert, D. N., Kalcic, M. T., and Faas, R. W.: Variability in the acoustic response of shallow-water marine sediments determined by normal-incident 30-kHz and 50-kHz sound, Mar. Geol., 182, 179-208, doi:10.1016/S0025-3227(01)00234-1, 2002.

McAnally, W. H., Teeter, A., Schoellhamer, D., Friedrichs, C., Hamilton, D., Hayter, E., Shrestha, P., Rodriguez, H., Sheremet, A., Kirby, R., and Fl, A. T. C. M.: Management of fluid mud in estuaries, bays, and lakes, II: Measurement, modeling, and management, J. Hydraul. Eng., 133, 23-38, doi:10.1061/(ASCE)0733-9429(2007)133:1(23), 2007.

Metha, A. J. and McAnally, W. H.: Fine-Grained Sediment Transport, in: Sedimentation Engineering: Processes, Measurements, Modeling and Practice, edited by: García, M. H., American Society of Civil Engineers, New York, p. 1132, 2008.

Missiaen, T., Slob, E., and Donselaar, M. E.: Comparing different shallow geophysical methods in a tidal estuary, Verdronken Land van Saeftinge, Western Scheldt, the Netherlands, 151-164, 2008.

Preisinger, A.: Sediments, in Neusiedlersee: The Limnology of a shallow lake in central Europe, in: Monographiae Biologicae volume 37, edited by: Löffler, H., Dr. W. Junk, The Hague, Boston, London, 131-138, 1979.

Sauerzopf, A. and Tauber, A. F. (Eds.): Landschaft Neusiedlersee, Grundriss der Naturgeschichte des Großraumes Neusiedlersee, Burgenländisches Landesmuseum, Amt der Bgld. Landesregierung, Abteilung XII/1-LM, Eisenstadt, AT, 1959.

Schettini, C. A. F. Ç., Almeida, D. C., Siegle, E., and Alencar, A. Ô. C. B. Ã.: A snapshot of suspended sediment and fluid mud occurrence in a mixed-energy embayment, Tijucas Bay, Brazil, GeoMar. Lett., 30, 47-62, doi:10.1007/s00367-009-0152-8, 2010.

Schmidt, J. and Csaplovics, E.: Mapping the Austrian reed bed of Lake Neusiedl by means of airborne optical scanner imagery, in International Symposium on Advanced Methods of Monitoring Reed Habitats in Europe, Illmitz, AT, 2010.

Schrottke, K., Becker, M., Bartholomä, A., Flemming, B. W., and Hebbeln, D.: Fluid mud dynamics in the Weser estuary turbidity zone tracked by high-resolution side-scan sonar and parametric sub-bottom profiler, Geo-Mar. Lett., 26, 185-198, doi:10.1007/s00367-006-0027-1, 2006.
Seifert, A. and Kopf, A.: Modified Dynamic CPTU Penetrometer for Fluid Mud Detection, J. Geotech. Geoenviron. Eng., 138, 203-206, doi:10.1061/(ASCE)GT.1943-5606.0000563, 2012.

Seifert, A., Stegmann, S., Mörz, T., Lange, M., Wever, T., and Kopf, A.: In situ pore-pressure evolution during dynamic CPT measurements in soft sediments of the western Baltic Sea, Geo-Mar. Lett., 28, 213-227, doi:10.1007/s00367-008-0102-x, 2008.

Shi, Z., Ren, L. F., and Lin, H. L.: Vertical suspension profile in the Changjiang Estuary, Mar. Geol., 130, 29-37, doi:10.1016/00253227(95)01396-2, 1996.

Soja, A.-M. and Soja, G.: Deliverable 3.1.2, Colonisation History by Harmful Algue; Lake 10 Neusiedl, Project EULAKES Ref. Nr. 2CE243P3, Tulln, Austria, available at: http://www.eulakes.eu/upload/eulakes/gestionedocumentale/ 3.1.220final20N_7842662.pdf, last access: 25 September 2014.

Tauber, A. F.: Trübung und Sedimentverfrachtung im Neusiedlersee, in: Landschaft Neusiedlersee, Grundriss der Naturgeschichte des Großraumes Neusiedlersee, edited by: Sauerzopf, A. and Tauber, A. F., Burgenländisches Landesmuseum, Amt der Bgld. Landesregierung, Abteilung XII/1-LM, Eisenstadt, AT, 81-88, 1959.

Teeter, A. M.: The viscous characteristics of channel-bottom muds, Technical Note DRP-2-04, US Army Engineer Waterways Experiment Station, Vicksburg, MS, 1992.

Tolotti, M.: Transnational Output 3.1.4, Final transnational report on long term ecological evaluation of CE lakes, Project EuLakes Ref. Nr. 2CE243P3, Istituto agrario di San Michele all'Adige, Fondazione Edmund Mach di San Michele all'Adige, San Michele All'adige, Italy, 2012.

Whitehouse, R., Soulsby, R., Roberts, W., and Mitchener, H.: Dynamics of Estuarine Muds: A Manual for Practical Applications, Thomas Telford, Wallingford, England, UK, 2000.

Wolanski, E., Asaeda, T., and Imberger, J.: Mixing across a lutocline, Limnol. Oceanogr., 34, 931-938, 1989. 